Ethiopian Journal of Environmental Studies \& Management 9 (2): 228 - 234, 2016.

ISSN:1998-0507

doi:http://dx.doi.org/10.4314/ejesm.v9i2.10

Submitted: December 15, 2015

Accepted: April 07, 2016

\title{
THE EFFECT OF TRANSPORTATION IN LOGISTICS OPERATION ON AN ENTREPRENEURIAL PERFORMANCE
}

\author{
*OBASAN, K.A., OGUNKOYA, O.A. AND HASSAN, B.A. \\ Department of Business Administration, Olabisi Onabanjo University, Ago-Iwoye \\ Ogun State, Nigeria
}

\begin{abstract}
The need for transportation in logistic operation cannot be undermined if a business is to stay competitive in a globalised economy. Improvements in customer awareness have made industries to use logistics as an important tool to increase returns, improve operational efficiency and performance. This study examined the effect of transportation in logistics operation on an entrepreneurial performance. The research employed a survey research with a self-structured questionnaire using a multistage sampling techniques and a simple random selection. A sample of 150 staff from 10 selected entrepreneurial firms in Lagos and Ogun state distributing 15 questionnaires each to them to form the basis of the data. The data gathered for the study after being hypothesized were analysed using descriptive statistic, $T$ test and regression analysis. The result of the findings showed that there is a strong and significant relationship ( $r=0.784)$ between transportation in logistics operation and entrepreneur performance and also that transportation in logistics operation has significant effect on entrepreneurial performance with a T-test value of value 0.00 . Thus, it is concluded that transportation in logistics operation is an effective tool entrepreneurs can employ in the quest to remain competitive and effective in their operations.
\end{abstract}

Key Words: Transportation, Logistics Operation, Entrepreneur, Performance

\section{Introduction}

The foundation of trade is the ability to move or transport a product from the source to the consumers and still make a profit (Landes, 1998). The foundation of businesses can be described with the two fundamental major problems: finding or creating demand and how to supply it while the performance thereafter reflects the outcome of the implementation of any strategic task and whether such outcome is deemed to be successful or disastrous.

The growing importance of logistics arises from entrepreneurial and already developed company becoming globalized to gain access to new markets, realize greater production efficiencies, and tap technological competencies beyond their own geographical borders (McFarlan, 1984; Bovet, 1991; Cooper, 1993; Fawcett et al., 1993).

Logistics includes everything from the movement of a product or from a service that needs to be rendered, through to the management of incoming raw materials, production, the storing of finished goods, its delivery to the customer and after-sales service (Pollitt, 1998). The current

*Corresponding Author: Obasan, K.A. 
The Effect of Transportation in Logistics Operation on an Entrepreneurial.................OBASAN et al.

logistics operations include purchasing, distribution, the managing of inventories, packaging, manufacturing, and even customer services (Bowersox and Closs, 1996). Of concern, however, to transportation in an enterprise is the Shipping, forwarding, (de)consolidation, contract delivery, freight bill payment/audit, household goods, relocation, load tendering and brokering (Sink et al., 1996).

The significance of enterprise freight transport and logistics is gradually increasing in the global economy, thus the optimization of the connecting business and technological processes might provide a serious monetary advantage. Accordingly, entrepreneurs today are looking for opportunities to improve operational efficiencies and reduce cost without having a negative effect on customer service levels (Vinod, 2009). However, transport costs represent a significant share of the final price in an enterprise.

Both Christopher (1998) and Riggs and Robbins (1998) pointed out three key drivers for performance in the logistic of an enterprise: Better quality/service, lower transport costs and faster transport time. Hence, lower transport costs mean cost efficient solutions, which could reduce costs through larger volumes, lower use of fuel, lower demand for labour force etc. and lower externalities i.e unrecovered costs since they represent a cost to society which is not recovered through conventional market mechanisms (GRIAN, 2010). All these three factors address efficient transport in logistics operations for an entrepreneur. Thus, increased performance might occur by achieving these factors. Therefore the present study seeks to answer the questions: what is the effect of transportation in logistics operation on the entrepreneurial performance, what is the relationship between transportation in logistics operation and entrepreneurial performance? Based on these questions, hypothesis was tested as follows:

$\mathrm{H}_{0}$ : Transport in logistics operation has no significant effect on entrepreneurial performance.

$\mathrm{H}_{1}$ : Transport in logistics operation has significant effect on entrepreneur performance.

\section{Literature Review}

Enterprise performance is an important business outcome that has been widely researched in the management literature. Drawing from the extensive literature, it is argued that high-level business performance is associated with business success and survival (Lai et al., 2010). In the supply chain management literature, logistics integration is considered one of the important precursors to financial and enterprise performance (Wheeler 2002; Louw and Venter 2006: 119; Lai et al. 2010).

Thomas, Deepak and Shashank, (2014), defined logistics as "that part of supply chain management that plans, implements, and controls the efficient, effective forward and reverse flow and storage of goods, services and related information from the point of origin to the point of consumption in order to meet customers' requirements", wherefore, transportation is represented in this expression through the word "flow". Transportation provides the flow of inventory from points of origin in the supply chain to destinations, or points of use and consumption. Most businesses manage both inbound and outbound 
logistics (Thomas et al., 2014). Inbound logistics involves the procurement of materials and goods from supplier locations. Outbound logistics involves the distribution of materials and goods to customer locations. Therefore, transportation is necessary on the inbound and outbound sides of the optimal business performance for an entrepreneur. This optimal performance requires an understanding of how the various logistical decisions and actions affect service for customers and total cost.

Logistics integration is an essential and indispensable element of supply chain management (Chen and Paulraj, 2004; Ballou, 2007), without which value creation might be difficult to attain (Lai et al., 2004). This is because logistics integration leads to a reduction in operational costs and an improvement in customer services (Richardson, 1995: 60; Ballou, 2004: 13; Lai et al., 2004). Furthermore, the integration of logistics activities within other functional areas may help bring an enterprise to realise the full potential of its value-added activities and, hence, to gain a significant competitive advantage (Rutner and Langley, 2000; Coyle, Bardi and Langley 2003: 34; Louw and Vente,r 2006).

However, despite the popularity of the integrated logistics concept and its many applications, for example, in supply-chain management and efficient consumer response, very few studies have investigated it from the perspective of small and medium-sized enterprises (SMEs). Previous researchers (Carbone and Stone, 2005; Wen et al., 2011) have focused mainly on the importance of strategic purchasing in service and hightechnology industry; the impact of transportation on logistics performance
(Kengpol, 2007; Lai et al., 2008; Lee et al., 1997; Rogers et al., 1992); and the buyer-supplier relationship in supply chain management and business performance (Lai et al., 2004), among others, in large business entities.

There is a dearth of studies on similar focus in the context of the small and medium enterprises (SMEs) sector particularly in Africa. This is unfortunate given that SMEs are regarded as the engine of economic growth and a vehicle of employment creation in both developed and developing countries (Chinomona and Pretorius, 2011). Besides, it would be naïve to assume a priori that findings from developed countries in Europe or from the USA, or even from the newly developed countries in Asia, would apply in Africa. Thus, in order to confirm or disconfirm the findings of previous studies, this research related to transportation in logistics operation for entrepreneurial performance becomes vital.

Chinomona (2013) studied the effect of logistics in IT's on SME's. The data for his research were collected from Harare, and the largest city in Zimbabwe, with a sampling frame of Small to Medium Enterprise Association of Zimbabwe. The result of his analyses indicated a robust relationship between logistics integration and SMEs' performance $(\mathrm{r}=0.891)$, which signifies the paramount importance and contribution of logistics integration to business performance. Prior evidence has also found a positive relationship between logistics integration and business performance (Kim 2006), and hence concluded that SMEs' logistics integration with their suppliers and customers can be expected to improve their business performance. 
Based on a European business database (from Kompass (2005), Helders (2008), Aéroports Magazine (2004), Containerisation International (2008), International Transport Journal (2008).), César and Martijn (2008), analyses the modal portfolio and employment distribution of about 8,000 transport firms, intermodal operators, and freight forwarders among 80 European ports. It allows measuring the degree to which different industries such as port activities, logistics, warehousing, road, sea, river, rail, and air transport, integrate within firms and within ports. Main results of the quantitative analysis show that transport integration and port performance have significant interdependence; also, their result shows that while logistics and road transport have many relations with air and rail transport, they have few relations with water transport in general. They however, concluded that though the statistical relationship between transport integration and port performance is significant, but it is influenced by different regional legacies and contexts.

According to Jeroen (2010), the various modes of transport (road, waterways, rail, air and sea) have responded to increasing demand in different ways, and road transport has grown the fastest. As Baseline Report (2004) explained that often where goods are moved by rail, water or air the road network forms an immediate extra link in the supply chain, besides, road is the only transport infrastructure that links virtually all possible points of collection or delivery of goods. So to say, efficient road transport plays an essential role in logistics operations.

Virtually, entrepreneurs less obvious cost-saving strategies must include numerous keys, like recycling, waste reduction, transportation, in-house design, minimal packaging and economies of scale for the sake of examples. And certainly, these cost-saving strategies more or less concern efficient road transport in logistics operations, in a manner they could be executed by achieving efficient transportation for an entrepreneurial business performance.

\section{Methodology}

The study was carried out in Lagos and Ogun state. Lagos state is the largest city in Nigeria and the African continent and is seen to be a major financial centre in Africa with the highest GDP. Its coordinates are given as $6.455027^{\circ} \mathrm{N}$ $3.384082^{\circ} \mathrm{E}$. Lagos was the capital of Nigeria since its amalgamation in 1914 till it was moved to Abuja in 1991. The National Bureau of Statistics in 2015 estimates the population of the area at approximately 21 million. Ogun state on the other hand was created in 1976 and is in South-Western Nigeria. The state is strategically located; bordered to the east by Ondo State and to the north by Oyo and Osun States. Its border with the Republic of Benin, to the west, makes it an access route to the expansive market of the Economic Community of West African States (ECOWAS), to the south by Lagos, the commercial nerve centre of the country. It has a land area of 16,409.26 square kilometres and its coordinates given as $7^{\circ} 00^{\prime} \mathrm{N} 3^{\circ} 35^{\prime} \mathrm{E}$.

This study focused on the effect of transportation in logistics operation on an entrepreneurial performance. This research employed a survey research with a selfstructured questionnaire by using a multistage sampling method. The first stage involves the selection of the two states in 
Nigeria: Lagos and Ogun States in Nigeria. The second stage involve the selection of five local government each from the selected state namely: Lagos (Ikeja, IfakoIjaye, Agege, Alimosho and Kosofe) and in Ogun (Ijebu-Ode, Ijebu-North, Shagamu, Abeokuta North and South respectively) and in the third stage a random selection of an entrepreneur whose staff are up to or more than 15 in the selected areas. Thus, a sample of 150 staff employed by entrepreneurs and small business owners was selected from the 10 selected in Lagos and Ogun state. There were administered questionnaires and the data generated were analysed using descriptive statistical analysis, regression and a t-test to test the hypothesis on the effect and relationship on the transportation in logistics operation on an entrepreneur performance. The formula is as written below:

$$
\mathrm{T}_{\mathrm{c}}=\frac{\mathrm{X}-\mu}{\delta / \sqrt{\mathrm{n} n}}
$$

Where: $T_{c}=$ is the $T$-test calculated for the test, $\mathrm{X}=$ is the mean (This is further written as $\left.\sum x / n\right), \mu=$ is the number of the sampled/population means, $\delta=$ is the standard deviation [It is written as $\sqrt{ }\left(\sum(\mathrm{x}-\right.$ $\left.\left.\mathrm{x})^{2} / \mathrm{n}-1\right)\right] \mathrm{n}=$ is the number of sample, $\mathrm{n}-1$ $=$ Degree of freedom.

$\mathrm{Y}=\mathrm{a}+\mathrm{b}_{\mathrm{i}} \mathrm{x}_{\mathrm{i}}+\mathrm{b}_{2} \mathrm{x}_{2} \ldots \ldots \ldots \ldots \ldots+\mathrm{e}_{\mathrm{i}}$

Where $\mathrm{Y}$ is the dependent variable, $\mathrm{a}$ is the constant, $b$ are the coefficients of independents $\mathrm{x}$.

\section{Result and Discussion}

Table 1: Showing Description of the Socio-Economic Characteristics of Respondents

\begin{tabular}{llll}
\hline VARIABLE & CATEGORY & FREQUENCY & PERCENTAGE \\
\hline Gender & Male & 112 & $74.7 \%$ \\
Age & Female & 38 & $25.3 \%$ \\
& $21-30$ years & 51 & $34 \%$ \\
& $31-40$ years & 36 & $24 \%$ \\
Marital Status & $41-50$ years & 33 & $22 \%$ \\
& 51 and above & 20 & $20 \%$ \\
& Single & 98 & $65.3 \%$ \\
& Married & 45 & $30 \%$ \\
\hline
\end{tabular}

Table 1 above shows that $65.3 \%$ of the respondents were single, $30 \%$ were married while $4.7 \%$ are divorcee. More so, $74.7 \%$ were males while $25.3 \%$ were females. Also, $34 \%$ are between age range of 21-30yrs, $24 \%$ fall within age range of 31-40 years, $22 \%$ are between age range of 41-50yrs and (20\%) are 51yrs and above.

Table 2: Showing One-Sample Test and Test of Homogeneity of Variances

\begin{tabular}{llllllll}
\hline Variable & Levene test & \multicolumn{2}{l}{ Test Value $=148$} & & \\
\hline Effect & 0.00 & T & Df & Sig. & Mean & 95\% Confidence & Interval of the \\
& & & & $(2$ tailed) & Difference & Difference & \\
& & 19.176 & 149 & .000 & 2.30455 & Lower & Upper \\
& & & & & 2.0664 & 2.5427 \\
\hline
\end{tabular}


Table 3: Showing Model Summary and Test of hypothesis of the relationship between transportation in logistics operation on entrepreneur performance

\begin{tabular}{llllllllll}
\hline Variables & & & $\mathrm{R}$ & $\mathrm{R}^{2}$ & $\mathrm{Fc}$ & $\mathrm{Ft}$ & $\mathrm{Df1}$ & $\mathrm{Df2}$ \\
\hline $\begin{array}{l}\text { Transportation } \\
\text { entrepreneurial performance }\end{array}$ & $\begin{array}{c}\text { in logistics } \\
\text { operation }\end{array}$ & and & .784 & .528 & $3.3295 \mathrm{E} 3$ & 9.777 & 9 & 141 \\
\hline
\end{tabular}

From table 2, the significance level for the Levene's test is 0.00 , this is lower than the cutoff of 0.05 , thus the assumption of equal variances is violated, and therefore the $\mathrm{T}$-value for the second row is used. Therefore in assessing whether transport in logistics operation has significant effect on the entrepreneur performance, the value of the sig. (2-tailed) column on the second row is 0.00 ; this is less than 0.05 level of significant, thus indicating that there is a significant effect of transport in logistics operation on entrepreneur performance. Thus the alternate hypothesis (H1) which states that transport in logistics operation has significant effect on entrepreneurial performance is accepted while the null hypothesis is rejected. This indicates that effect of transportation in logistics is significant. Also, table 3 above reveal the correlation coefficient $(r=0.784)$ of the linear regression result which shows that there is a strong positive relationship between transportation in logistics operation and entrepreneur performance while $\left(\mathrm{r}^{2}=0.528\right)$ is the coefficient of determination reveal that $52.8 \%$ of the variation in entrepreneur performance is explained by transportation in logistics operation while the remaining $48.2 \%$ of the variation in entrepreneur performance is explained by other factors aside from transportation in logistics operation.

The $\mathrm{F}$ calculated is given as 33.295, critical value at $5 \%$ level of significance gives 9.777 (the $\mathrm{F}$ table value is 9.777). Since the calculated value is greater than the table value i.e. $(\mathrm{Fc}>\mathrm{Ft})$, therefore we reject $\mathrm{H}_{0}$ (null hypothesis) which states that "there is no significant relationship between transportation in logistics operation and entrepreneur performance". The result of this analysis attests to the result of Chinomona (2013) with significant relationship of (0.891), and concluded that it signifies the paramount importance and contribution of logistics integration to business performance. Prior evidence has also found a positive relationship between logistics integration and business performance (Kim, 2006). The result is also evidenced from the study conducted by César and Martijn (2008) with logistic transportation integration correlation of 0.71 relationships.

\section{Conclusion and Recommendation}

This study examined the effect of transportation in logistics operation on an entrepreneurial performance. The above results indicate that the transportation in logistic operation has effect and relationship on entrepreneurial performance. This result is an indication that companies today are challenged to streamline their transportation and logistics management process to maximize efficiencies, customer satisfaction and profit margins. It is therefore, recommended that for an entrepreneurial performance to be maintained, they should ensure their transport in logistics is well integrated and plans that is driven by consumer demand and replenishment policy, control costs and streamline productivity, leverage logistics to support 
profitable growths and finally improve trading partners relationships with effective collaboration.

\section{References}

Bovet, D. (1991). "Logistics strategies for Europe in the 1990s", Planning Review, July/August, pp. 12-15, 46-8.

Bowersox, D.J. and Closs, D.J. (1996). Logistics Management - The Integrated Supply Chain Process, McGraw-Hill, New York, NY

Chinomona, R. (2013). The fostering role of information technology on SMEs' strategic purchasing, logistics integration and business performance. Zimbabwe distribution channels', African Journal of Business, 17(1): 76-97.

Christopher, M (1998): Logistics and Supply Chain Management, Prentice Hall, London.

Cooper, J.C. (1993). "Logistics strategies for global businesses", International Journal of Physical Distribution \& Logistics Management, 23(4): 12-23.

Fawcett, S.E., Birou, L.M. and Taylor, B.C. (1993). "Supporting global operations through logistics and purchasing", International Journal of Physical Distribution \& Logistics Management, 23(4): 3-11.

GRIAN (Greenhouse Ireland Action Network Ltd.), (2006). Media advisory: the real costs of road transport, Brookfield Place, Blackrock, Co. Dublin.

Kim, S.W. (2006). 'Effects of supply chain management practices, integration and competition capability on performance', Supply Chain Management: An International Journal, 11(3): 241-248.

Landes, D.S. (1998). The Wealth and Poverty of Nations. W.W. Norton \& Company, New York

McFarlan, F.W. (1984). "Information technology changing the way you compete", Harvard Business Review, 57(2): 115-26.

Pollitt, D. (1998). "View point: getting logistics on to boardroom agenda", International Journal of Physical Distribution \& Logistics Management, 2(3):168-9.

Riggs, D.A. and Robbins S.L. (1998). The Executive's Guide to Supply Management Strategies, New York, AMACOM.

Sink, H.I., Langley, C.J. and Gibson, B.J. (1996). "Buyer observations of the US third-party logistics market", International Journal of Physical Distribution \& Logistics Management, 30(5): 36-46.

Vinod, L. (2009). Reducing Costs through Production and Supply Chain Management, QFINANCE. 